\title{
A Simple and Rapid Extraction Method of Carbohydrates from Petals or Sepals of Four Floricultural Plants for Determination of Their Content
}

\author{
Ryo Norikoshi ${ }^{1,2}$, Hideo Imanishi ${ }^{2}$ and Kazuo Ichimura ${ }^{1 *}$ \\ ${ }^{1}$ National Institute of Floricultural Science, Fujimoto, Tsukuba 305-8519, Japan \\ ${ }^{2}$ Tokyo University of Agriculture, Funako, Atsugi 243-0034, Japan
}

\begin{abstract}
We developed a simple and rapid extraction method of soluble carbohydrates from petals for analysis by high performance liquid chromatography (HPLC), using a centrifugal filter device in a test tube without homogenization. Rose 'Sonia' petals were immersed in $99.5 \%$ ethanol solution in a test tube and kept at $75^{\circ} \mathrm{C}$ for $20 \mathrm{~min}$. Sorbitol was then added to the solution as an internal standard, and the petals were transferred to the centrifugal filter device and centrifuged at $12000 \times \mathrm{g}$ for $10 \mathrm{~min}$. Following removal of the filtrate, $99.5 \%$ ethanol was added to the filter device and a second round of centrifugation performed. Filtrated solution obtained from both centrifugations was combined with the ethanol solution remaining in the test tube, heated to dryness at $80^{\circ} \mathrm{C}$, and used for HPLC analysis. Few differences in soluble carbohydrate content were observed between the new method and a conventional method in which soluble carbohydrates are extracted by homogenization. We confirmed that most carbohydrate was extracted by the new method. Moreover, the soluble carbohydrate content of samples extracted from 'Sonia' petals using the new method did not change during one week of storage at $-30^{\circ} \mathrm{C}$, indicating the stability of the samples. Marked differences in soluble carbohydrate content were not observed among 'Chanel', 'New Bridal', 'Rote Rose', or 'Saturn' rose petals, carnations or Tweedia caerulea petals or Delphinium sepals, using either the new or conventional method. Marked differences in soluble carbohydrate content were also not observed among leaves and stems in carnations, Delphinium or rose 'Sonia' using either the new or conventional method. These results suggest that the new method, which does not require homogenization, appears to be a more simple and rapid method of extraction of soluble carbohydrates from various organs of floricultural plants.
\end{abstract}

Key Words: carbohydrate extraction, carnation, Delphinium, rose, Tweedia caerulea.

\section{Introduction}

Soluble carbohydrates have an osmotic role and also provide substrates for respiration and cell wall synthesis. Since cut flowers are usually placed under conditions below the light compensation point for photosynthesis, they can assimilate little carbon by photosynthesis, and thereby lack reserve carbohydrates. Application of sugars, such as sucrose and glucose, extends the vase life of many cut flowers (Halevy and Mayak, 1979; Pun and Ichimura, 2004). In addition, sugar promotes flower opening and petal pigmentation (Halevy and Mayak, 1979; Ichimura, 1998).

Cut roses rarely open fully, which is attributed to the shortage of soluble carbohydrates (Ichimura et al., 2003); however, cut flowers of some cultivars, including

Received; May 7, 2007. Accepted; December 19, 2007.

* Corresponding author (E-mail: ichimu@affrc.go.jp).
'Delilah' roses, open fully. This is attributed to a high concentration of soluble carbohydrate in the petals at the time of harvest (Ichimura et al., 2005). In some ethylene-sensitive flowers, such as carnations and Delphinium flowers, treatment with sucrose and glucose reduces sensitivity to ethylene and delays the climacteric increase in ethylene production, thereby extending their vase life (Dilley and Carpenter, 1975; Ichimura et al., 2000). In cut sweet pea flowers, there is a positive correlation between soluble carbohydrate concentrations in petals and vase life (Ichimura and Suto, 1999). These findings indicate that the determination of soluble carbohydrate content is important for understanding the post-harvest physiology of cut flowers.

High performance liquid chromatography (HPLC) is often used to determine soluble carbohydrate content since it is easy to perform and yields reproducible results. To perform HPLC analysis, soluble carbohydrate must be extracted from plant tissue. Traditionally, petals are 
immersed in hot ethanol solution and then homogenized. The homogenate is centrifuged and the resulting supernatant concentrated to remove ethanol (Doi et al., 2000; Ichimura et al., 1997; Koyama et al., 1995; Ogiwara et al., 1999), which is laborious and timeconsuming. To extract soluble carbohydrates, cell membranes should be decomposed. Immersing plant tissue in hot water has been shown to decompose cell membranes, leading to measurable increases in electroconductivity due to electrolytes leaked from plant cells (Sasaki et al., 1996). We supposed that a sufficient portion of soluble carbohydrate for analysis would leak from tissue by immersion in hot water or hot ethanol solution without requiring a homogenization step.

Previously, we developed a simple and rapid extraction method using a centrifugal filter device to determine soluble carbohydrate concentrations in petals (Norikoshi et al., 2006). To perform this method, tissue was frozen in liquid nitrogen and then centrifuged. The resulting filtrate was then analyzed for soluble carbohydrate content by HPLC; however, soluble carbohydrate was not completely extracted and therefore the absolute carbohydrate content can not be determined using this method. Furthermore, the concentrations of extracted soluble carbohydrates were observed to vary over time, even when samples were maintained at low temperature. This may be due to the activity of certain enzymes, such as invertase. To inactivate unwanted enzyme activity, hot ethanol is widely used as a carbohydrate extraction medium (Ichimura et al., 1997; Koyama et al., 1995).

In the present study, we developed a simple and rapid extraction method without homogenization to determine the soluble carbohydrate content of petals from several flowers. In the preparation of samples for HPLC analysis, some carbohydrate is inevitably lost. Thus, an internal standard was used in the present study for accurate determination of carbohydrate content.

\section{Materials and Methods}

\section{Plant materials}

Cut rose 'Chanel', 'New Bridal', 'Rote Rose', 'Saturn', and 'Sonia' flowers at normal harvest maturity were obtained from a grower in Namekata city in Ibaraki prefecture. Delphinium hybrid cv. Bellamosum, carnation 'Barbara' and Tweedia caerulea D. Don were grown in a greenhouse of the National Institute of Floricultural Science. Petals, sepals, leaves, and stems were collected from plants after flowers had fully opened.

\section{Simple and rapid extraction method}

Petals, sepals or leaves were cut into pieces (approx. $5 \mathrm{~mm}$ squares), whereas stems were cut horizontally with a thickness of approx. $3 \mathrm{~mm}$. The tissue pieces $(0.2 \mathrm{~g}$ FW) were immersed in $2 \mathrm{~mL}$ of $99.5 \%$ ethanol in a test tube and heated at $75^{\circ} \mathrm{C}$ for $20 \mathrm{~min}$. Then, $25 \mu \mathrm{L}$ of $10 \%$ sorbitol solution was gently stirred into each sample as an internal standard. The petal pieces were transferred into a centrifugal filter device (Ultrafree MC, $0.45 \mu \mathrm{m}$, Millipore, Medford, MA, USA), and the remaining solution in the test tube was designated A solution. The filter device was subjected to centrifugation at $12000 \times$ $\mathrm{g}$ for $10 \mathrm{~min}$, and the filtrate was combined with $\mathrm{A}$ solution to make B solution. Then $0.5 \mathrm{~mL}$ of $99.5 \%$ ethanol was added to the tissue remaining in the filter device, which was then centrifuged a second time at $12000 \times \mathrm{g}$ for $10 \mathrm{~min}$. The filtrate was combined with $\mathrm{B}$ solution to make $\mathrm{C}$ solution. $\mathrm{A}, \mathrm{B}$ and $\mathrm{C}$ solutions were heated at $80^{\circ} \mathrm{C}$ for $30 \mathrm{~min}$ to evaporate to dryness, dissolved in $1 \mathrm{~mL}$ of distilled water, and then used for HPLC analysis. The procedure is illustrated in Figure 1. To determine the remaining carbohydrate content, the petals were transferred to a test tube, homogenized with a homogenizer (Ultra-Turrax T-25, Ika, Germany), and centrifuged at $3000 \times \mathrm{g}$ for $5 \mathrm{~min}$. The pellet was then twice re-extracted with $2.5 \mathrm{~mL}$ of $80 \%$ ethanol and the three supernatants were combined and dried in vacuo below $50^{\circ} \mathrm{C}$. The resulting supernatant was evaporated to dryness and dissolved in DW.

\section{Conventional extraction method}

The conventional method was conducted as previously described (Ichimura and Hisamatsu, 1999). Tissue pieces $(0.2 \mathrm{~g} \mathrm{FW})$ were collected from the same material sources as described above and immersed in $5 \mathrm{~mL}$ of $80 \%$ ethanol

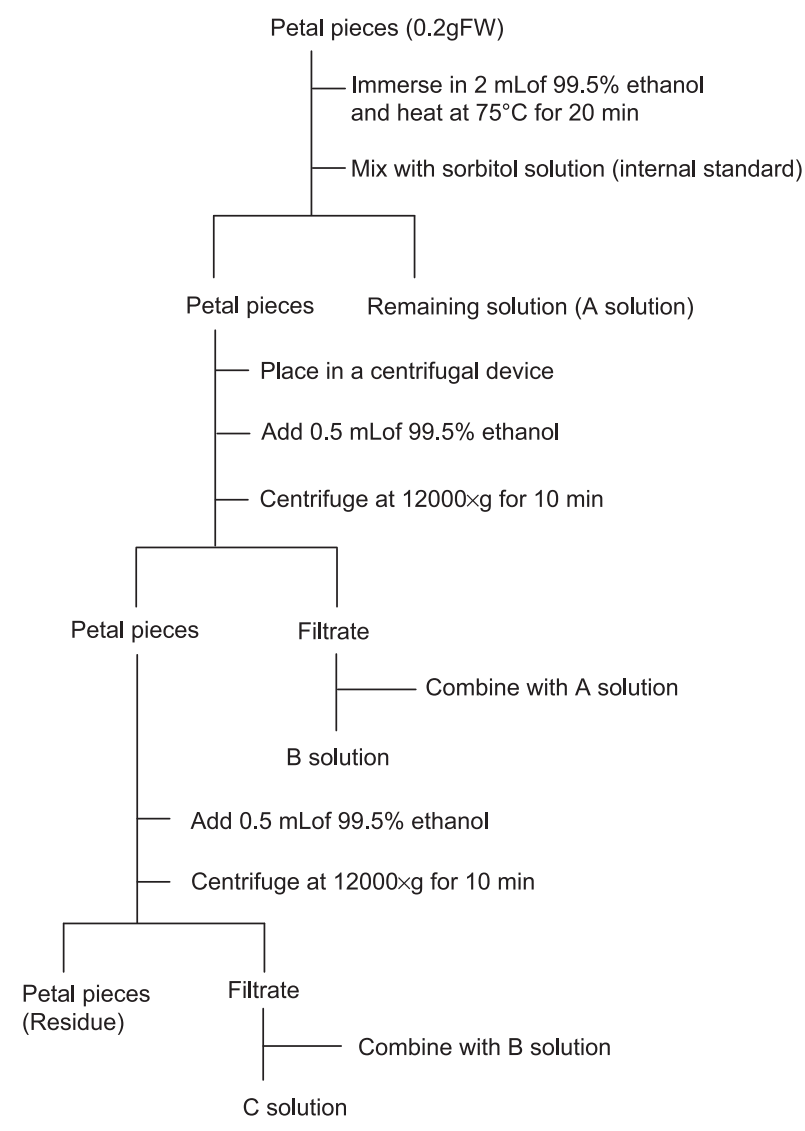

Fig. 1. Protocol for extraction of soluble carbohydrates. 
at $75^{\circ} \mathrm{C}$ for $30 \mathrm{~min}$. After cooling, $50 \mu \mathrm{L}$ of $50 \mathrm{~g} \cdot \mathrm{L}^{-1}$ sorbitol was added to the sample as an internal standard. The sample was then homogenized and centrifuged at $3000 \times \mathrm{g}$ for $5 \mathrm{~min}$. The pellet was twice re-extracted with $2.5 \mathrm{~mL}$ of $80 \%$ ethanol and the three supernatants were combined and dried in vacuo below $50^{\circ} \mathrm{C}$. The residue was resolved in $1 \mathrm{~mL}$ of distilled water and used for HPLC analysis.

\section{Determination of soluble carbohydrate content}

Carbohydrate was separated using an HPLC system (Jasco, Tokyo, Japan) equipped with a refractive index detector on a Shodex SUGAR SP0810 column (Showa Denko, Tokyo, Japan). The column was kept at $80^{\circ} \mathrm{C}$ and eluted with water at a flow rate of $0.8 \mathrm{~mL} \cdot \mathrm{min}^{-1}$. The identity of each peak was confirmed using authentic carbohydrate. The peak area was determined by an integrator and the amount of each carbohydrate in the sample was calculated as follows:

$$
\mathrm{WC}=\mathrm{WI} \cdot \mathrm{AS} / \mathrm{I} \cdot \mathrm{RF}^{-1} \text {, }
$$

where WC is the weight of each carbohydrate, WI is the weight of the internal standard (sorbitol), AS/I is the area of the carbohydrate peak relative to that of sorbitol, and $\mathrm{RF}$ is the relative response factor.

\section{Statistical analysis}

Data were taken from four independent experiments. The mean and standard deviation values were determined. Data were analyzed by t-test and Dunnett's test using Stat View software (v.5.0, SAS Institute Inc., Cary, NC, USA).

\section{Results}

Carbohydrate content of rose 'Sonia' petals determined after a three-step extraction process and the conventional method

After heating at $75^{\circ} \mathrm{C}$ for $20 \mathrm{~min}$, the volume of ethanol

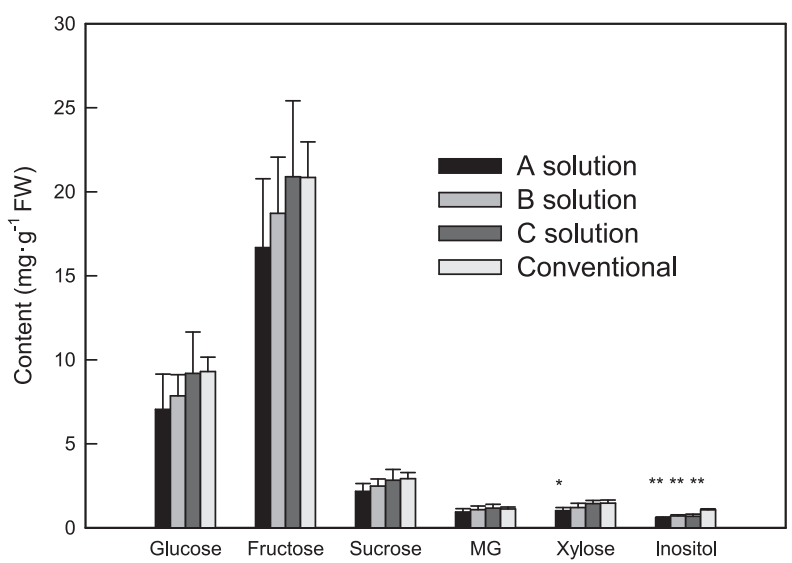

Fig. 2. Soluble carbohydrate content after extraction using the new and conventional methods. Values represent the means of 4 independent experiments $\pm \mathrm{SD}$. MG, methyl glucoside; Inositol, myo-Inositol. Columns marked by one and two asterisks significantly differ from values in the conventional method at $P<0.05$ and 0.01 , respectively, by Dunnett's test solution decreased to about $0.5 \mathrm{~mL}$. Glucose, fructose, sucrose, methyl glucoside, xylose and myo-inositol, were all detected in A, B, and C solutions (Fig. 2). Although a relatively high amount of these carbohydrates was found in A solution, it increased as extraction proceeded. HPLC elution profiles of soluble carbohydrate revealed that carbohydrates in samples from both the new and conventional methods were well separated (Fig. 3). Significant differences in the carbohydrate content of C solution and that obtained using the conventional method
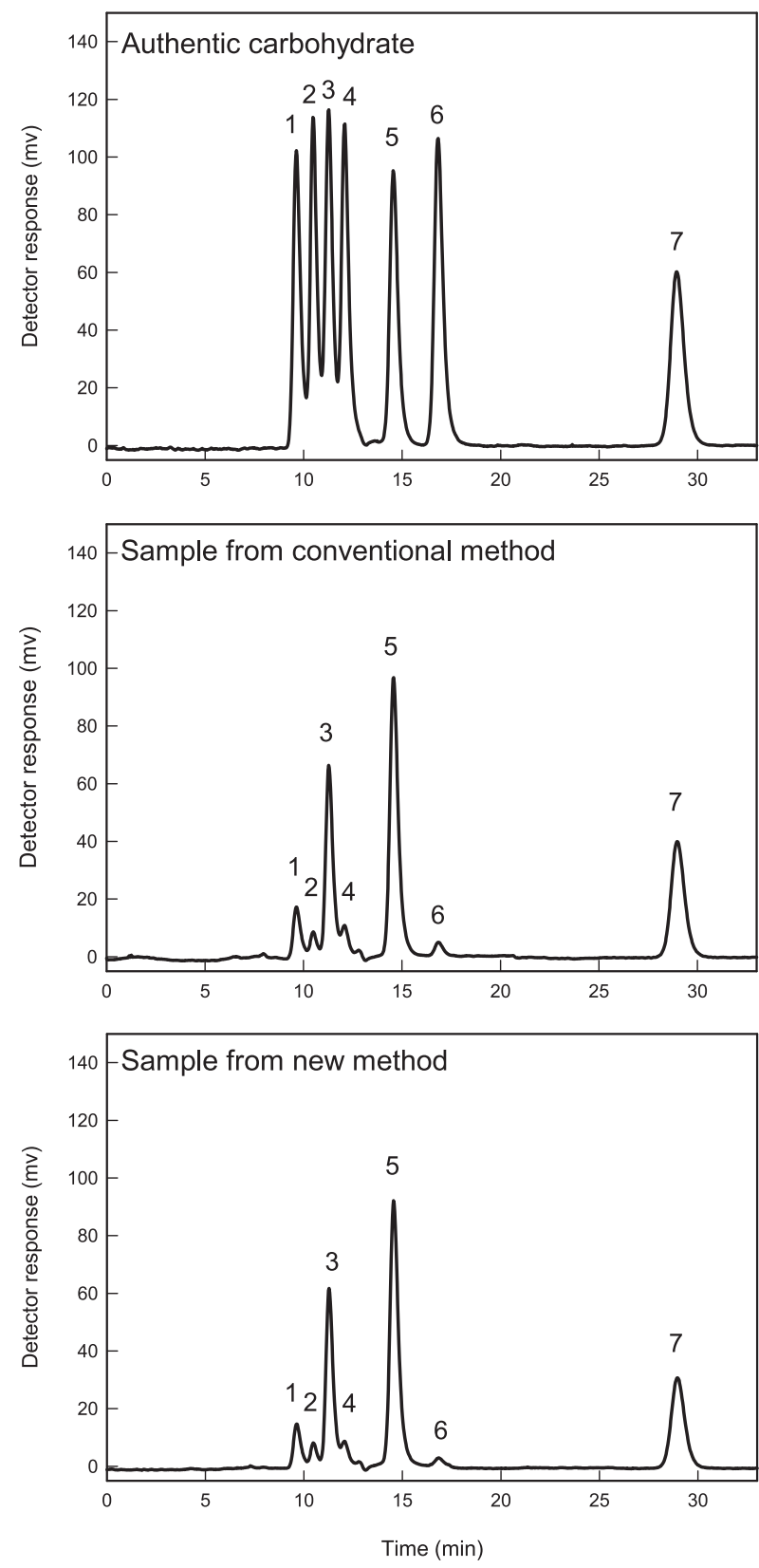

Fig. 3. HPLC elution profile of soluble carbohydrate after extraction using the new and conventional methods. Authentic carbohydrates (upper); sample from conventional method (middle); sample from new method (lower). 1, sucrose; 2, methyl glucoside; 3, glucose; 4, xylose; 5, fructose; 6, myo-inositol; 7, sorbitol (internal standard). Injected amount was $50 \mu \mathrm{L}$. For separation of authentic carbohydrate, concentration of each carbohydrate was $0.2 \%$. 
were not observed, except for myo-inositol (Fig. 2). Carbohydrate was extracted from the petal residue using the conventional method, after which the amount of each carbohydrate was determined. Compared with solution $\mathrm{C}$, minimal amounts were detected, suggesting that most carbohydrate was extracted by the procedure used to obtain C solution (Fig. 4). Based on these results, we adopted the same process used to obtain $\mathrm{C}$ solution in our subsequent experiments.

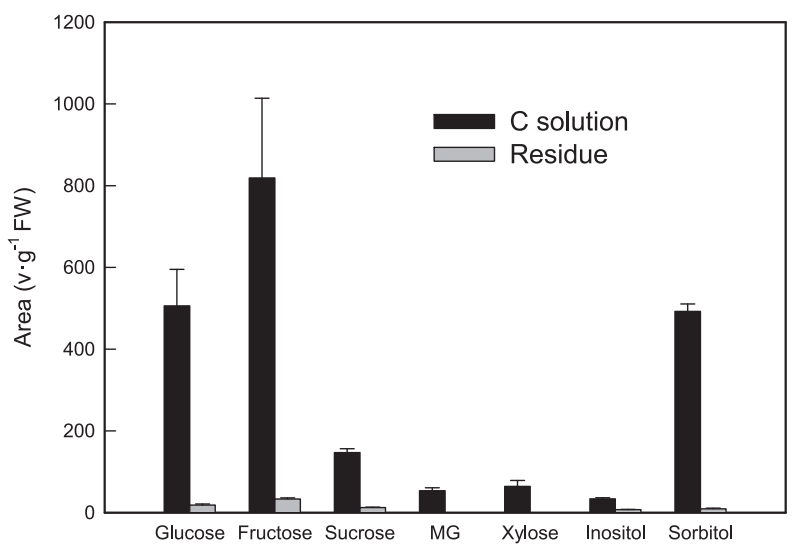

Fig. 4. Amounts of soluble carbohydrates in $\mathrm{C}$ solution extracted using the new method and in residue. Values represent the means of 4 independent experiments $\pm \mathrm{SD}$. C solution was obtained as described in Figure 1. MG, methyl glucoside; Inositol, myoInositol.

\section{Sample stability}

Carbohydrate samples extracted from rose 'Sonia' petals were stored at $-30^{\circ} \mathrm{C}$ for 1 day or 7 days, after which their carbohydrate content was determined. The carbohydrate content did not change significantly, regardless of the storage duration (Table 1).

\section{Soluble carbohydrate content in the petals of four rose cultivars}

Soluble carbohydrates were extracted from 'Chanel', 'New Bridal', 'Rote Rose', and 'Saturn' petals using the new and conventional methods, after which carbohydrate content was determined. For all cultivars, glucose, fructose, sucrose, methyl glucoside, myo-inositol, and xylose were detected in samples obtained by both methods (Table 2). Few differences in carbohydrate content were observed between the methods.

\section{Soluble carbohydrate content in the petals of carnations} and T. caerulea or sepals of Delphinium flowers

Soluble carbohydrate content in the petals or sepals of carnations, Delphinium and T. caerulea flowers was determined after extraction using the new and conventional methods. In carnation petals, glucose, fructose, sucrose, myo-inositol, and pinitol were detected in samples obtained by both methods (Table 3 ), and no significant difference in carbohydrate content was observed between the methods. In Delphinium sepals,

Table 1. Effects of storage periods of carbohydrate samples on the soluble carbohydrate content of 'Sonia' rose flowers.

\begin{tabular}{ccccccc}
\hline \hline \multirow{2}{*}{$\begin{array}{c}\text { Time stored } \\
\text { (days) }\end{array}$} & Glucose & Fructose & Sucrose & Methyl glucoside & myo-Inositol & Xylose \\
\cline { 2 - 7 } & $8.45 \pm 1.60^{\mathrm{z}}$ & $17.73 \pm 2.86$ & $3.15 \pm 0.67$ & $0.91 \pm 0.14$ & $0.60 \pm 0.21$ & $0.82 \pm 0.14$ \\
0 & $8.43 \pm 1.67$ & $16.92 \pm 3.62$ & $3.15 \pm 0.57$ & $0.88 \pm 0.09$ & $0.68 \pm 0.07$ & $0.99 \pm 0.14$ \\
1 & $8.12 \pm 1.18$ & $16.53 \pm 2.51$ & $3.18 \pm 0.35$ & $0.74 \pm 0.10$ & $0.66 \pm 0.10$ & $0.72 \pm 0.08$ \\
7 & &
\end{tabular}

z Values are the means of 4 independent experiments \pm SD.

Each carbohydrate content at 1 and 7 days was not significantly different at $P<0.05$ from each initial content (day 0 ) by Dunnett's test.

Table 2. Soluble carbohydrate content of petals in four rose cultivars.

\begin{tabular}{|c|c|c|c|c|c|c|c|}
\hline \multirow{2}{*}{ Cultivar } & \multirow{2}{*}{ Method } & \multicolumn{6}{|c|}{ Carbohydrate content $\left(\mathrm{mg} \cdot \mathrm{g}^{-1} \mathrm{FW}\right)$} \\
\hline & & Glucose & Fructose & Sucrose & Methyl glucoside & myo-Inositol & Xylose \\
\hline \multirow[t]{3}{*}{ Chanel } & Conventional & $10.26 \pm 1.28^{z}$ & $15.76 \pm 1.58$ & $4.32 \pm 0.66$ & $1.25 \pm 0.20$ & $0.99 \pm 0.30$ & $0.71 \pm 0.05$ \\
\hline & New & $10.05 \pm 1.09$ & $14.65 \pm 2.17$ & $3.82 \pm 0.56$ & $1.27 \pm 0.13$ & $0.40 \pm 0.25$ & $0.81 \pm 0.09$ \\
\hline & $t$-test $\mathrm{t}^{\mathrm{y}}$ & NS & NS & NS & NS & NS & NS \\
\hline \multirow[t]{3}{*}{ New Bridal } & Conventional & $8.62 \pm 0.83$ & $18.57 \pm 1.09$ & $4.75 \pm 0.34$ & $1.07 \pm 0.29$ & $2.27 \pm 0.32$ & $0.49 \pm 0.09$ \\
\hline & New & $8.99 \pm 0.63$ & $18.61 \pm 1.42$ & $4.95 \pm 0.35$ & $1.34 \pm 0.10$ & $1.44 \pm 0.17$ & $0.35 \pm 0.30$ \\
\hline & $t$-test & NS & NS & NS & NS & $*$ & NS \\
\hline \multirow[t]{3}{*}{ Rote Rose } & Conventional & $2.99 \pm 0.64$ & $4.69 \pm 1.26$ & $3.44 \pm 0.62$ & $0.14 \pm 0.14$ & $1.45 \pm 0.25$ & $0.25 \pm 0.20$ \\
\hline & New & $2.74 \pm 0.27$ & $4.80 \pm 1.64$ & $3.33 \pm 0.16$ & $0.32 \pm 0.34$ & $0.76 \pm 0.28$ & $0.34 \pm 0.23$ \\
\hline & $t$-test & NS & NS & NS & NS & $*$ & NS \\
\hline \multirow[t]{3}{*}{ Saturn } & Conventional & $8.35 \pm 2.05$ & $14.71 \pm 2.71$ & $5.56 \pm 1.26$ & $1.49 \pm 0.50$ & $1.83 \pm 0.14$ & $1.03 \pm 0.96$ \\
\hline & New & $7.38 \pm 1.11$ & $13.77 \pm 1.57$ & $5.25 \pm 1.06$ & $1.46 \pm 0.37$ & $1.13 \pm 0.55$ & $0.60 \pm 0.17$ \\
\hline & $t$-test & NS & NS & NS & NS & NS & NS \\
\hline
\end{tabular}

${ }^{\mathrm{z}}$ Values are the means of 4 independent experiments \pm SD.

${ }^{y} \mathrm{NS}, *$ indicate non-significant and significant at $P<0.05$, respectively, by $t$-test. 
Table 3. Soluble carbohydrate content of carnation and T. caerulea petals and Delphinium sepals.

\begin{tabular}{|c|c|c|c|c|c|c|c|}
\hline \multirow{2}{*}{ Species } & \multirow{2}{*}{ Method } & \multicolumn{6}{|c|}{ Carbohydrate content $\left(\mathrm{mg} \cdot \mathrm{g}^{-1} \mathrm{FW}\right)$} \\
\hline & & Glucose & Fructose & Sucrose & myo-Inositol & Pinitol & Mannitol \\
\hline \multirow[t]{3}{*}{ Carnation } & Conventional & $9.60 \pm 2.38^{z}$ & $20.97 \pm 4.36$ & $3.62 \pm 1.08$ & $0.68 \pm 0.12$ & $6.26 \pm 0.52$ & $\mathrm{ND}^{\mathrm{y}}$ \\
\hline & New & $7.57 \pm 1.99$ & $22.20 \pm 7.08$ & $2.31 \pm 1.00$ & $0.46 \pm 0.27$ & $4.75 \pm 1.27$ & ND \\
\hline & $t$-test $\mathrm{t}^{\mathrm{x}}$ & NS & NS & NS & NS & NS & - \\
\hline \multirow[t]{3}{*}{ Delphinium } & Conventional & $8.86 \pm 0.48$ & $10.72 \pm 0.41$ & $1.22 \pm 0.15$ & ND & ND & $12.89 \pm 2.10$ \\
\hline & New & $9.20 \pm 0.55$ & $11.12 \pm 0.95$ & $1.29 \pm 0.05$ & ND & ND & $12.95 \pm 2.54$ \\
\hline & $t$-test & NS & NS & NS & - & - & NS \\
\hline \multirow[t]{3}{*}{ T. caerulea } & Conventional & $20.08 \pm 1.60$ & $35.65 \pm 0.56$ & $8.42 \pm 0.44$ & $1.31 \pm 0.19$ & ND & ND \\
\hline & New & $18.02 \pm 1.37$ & $36.63 \pm 6.31$ & $7.66 \pm 0.24$ & $0.81 \pm 0.02$ & ND & ND \\
\hline & $t$-test & NS & NS & $*$ & $*$ & - & - \\
\hline
\end{tabular}

${ }^{z}$ Values are the means of 4 independent experiments \pm SD.

y ND, Not detected.

${ }^{x} \mathrm{NS}, *$ indicate non-significant and significant at $P<0.05$, respectively, by $t$-test.

Table 4. Soluble carbohydrate content in the leaves and stems of carnations, Delphinium and roses.

\begin{tabular}{|c|c|c|c|c|c|c|c|c|c|}
\hline \multirow{2}{*}{$\begin{array}{l}\text { Species and } \\
\text { organ }\end{array}$} & \multirow{2}{*}{ Method } & \multicolumn{8}{|c|}{ Carbohydrate content $\left(\mathrm{mg} \cdot \mathrm{g}^{-1} \mathrm{FW}\right)$} \\
\hline & & Glucose & Fructose & Sucrose & Pinitol & Mannitol & Methyl glucoside & Xylose & myo-Inositol \\
\hline \multicolumn{10}{|l|}{ Carnation } \\
\hline \multirow[t]{3}{*}{ Leaf } & Conventional & $2.02 \pm 0.77^{\mathrm{z}}$ & $2.07 \pm 1.02$ & $2.36 \pm 0.28$ & $9.90 \pm 0.37$ & $\mathrm{ND}^{\mathrm{y}}$ & ND & ND & $0.23 \pm 0.04$ \\
\hline & New & $2.25 \pm 0.62$ & $2.38 \pm 1.13$ & $2.25 \pm 0.38$ & $9.85 \pm 0.80$ & ND & ND & ND & $0.20 \pm 0.13$ \\
\hline & $t$-test $\mathrm{t}^{\mathrm{x}}$ & NS & NS & NS & NS & - & - & - & NS \\
\hline \multirow[t]{3}{*}{ Stem } & Conventional & $16.10 \pm 2.60$ & $1.28 \pm 0.72$ & $5.52 \pm 0.22$ & $7.18 \pm 0.65$ & ND & ND & ND & $0.25 \pm 0.07$ \\
\hline & New & $14.30 \pm 2.54$ & $1.20 \pm 0.34$ & $5.59 \pm 0.70$ & $6.75 \pm 1.54$ & ND & ND & ND & $0.19 \pm 0.08$ \\
\hline & $t$-test & NS & NS & NS & NS & - & - & - & NS \\
\hline \multicolumn{10}{|c|}{ Delphinium } \\
\hline \multirow[t]{3}{*}{ Leaf } & Conventional & $2.80 \pm 0.27$ & $3.60 \pm 0.43$ & $11.04 \pm 0.38$ & ND & $5.81 \pm 0.92$ & ND & ND & $1.95 \pm 1.14$ \\
\hline & New & $3.55 \pm 0.28$ & $4.11 \pm 0.34$ & $10.94 \pm 1.04$ & ND & $6.26 \pm 0.58$ & ND & ND & $1.82 \pm 1.46$ \\
\hline & $t$-test & NS & NS & NS & NS & - & - & - & NS \\
\hline \multirow[t]{3}{*}{ Stem } & Conventional & $5.19 \pm 0.43$ & $4.52 \pm 0.52$ & $10.59 \pm 0.84$ & ND & $9.00 \pm 1.52$ & ND & ND & $0.24 \pm 0.04$ \\
\hline & New & $4.28 \pm 1.10$ & $5.45 \pm 0.43$ & $8.32 \pm 1.60$ & ND & $7.68 \pm 1.52$ & ND & ND & $0.19 \pm 0.05$ \\
\hline & $t$-test & NS & NS & NS & NS & - & - & - & NS \\
\hline \multicolumn{10}{|l|}{ Rose } \\
\hline \multirow[t]{3}{*}{ Leaf } & Conventional & $1.96 \pm 0.19$ & $1.03 \pm 0.12$ & $19.86 \pm 0.80$ & ND & ND & $1.23 \pm 0.15$ & $0.59 \pm 0.05$ & $4.12 \pm 0.34$ \\
\hline & New & $2.30 \pm 0.22$ & $1.70 \pm 0.77$ & $19.50 \pm 1.28$ & ND & ND & $1.19 \pm 0.23$ & $0.56 \pm 0.08$ & $3.10 \pm 0.21$ \\
\hline & $t$-test & NS & NS & NS & - & - & NS & NS & $*$ \\
\hline \multirow[t]{3}{*}{ Stem } & Conventional & $1.58 \pm 0.10$ & $1.32 \pm 0.08$ & $8.48 \pm 1.11$ & ND & ND & $2.33 \pm 0.49$ & $0.48 \pm 0.08$ & $0.57 \pm 0.09$ \\
\hline & New & $1.13 \pm 0.29$ & $1.76 \pm 0.23$ & $7.53 \pm 0.74$ & ND & ND & $2.13 \pm 0.28$ & $0.61 \pm 0.13$ & $0.81 \pm 0.18$ \\
\hline & $t$-test & NS & $*$ & NS & - & - & NS & NS & NS \\
\hline
\end{tabular}

z Values are the means of 4 independent experiments \pm SD.

y ND, Not detected.

${ }^{x} \mathrm{NS}, *$ indicate non-significant and significant at $P<0.05$, respectively, by $t$-test.

glucose, fructose, sucrose, and mannitol were detected in samples obtained by both methods, and no significant difference in carbohydrate content was observed between the methods. In T. caerulea petals, glucose, fructose, sucrose, and myo-inositol were detected in samples obtained by both methods, and no significant difference in the carbohydrate content was observed between the methods, except for sucrose and myo-inositol.
Soluble carbohydrate content in the leaves and stems of carnations, Delphinium and roses

Soluble carbohydrate content in the leaves and stems of carnations, Delphinium, and roses was determined after extraction using the new and conventional methods. In these plants, no significant difference in carbohydrate content was observed between the methods, except for myo-inositol in leaves and fructose in the stems of roses (Table 4). 


\section{Discussion}

In the present study, soluble carbohydrates could be extracted by immersing petal tissue in hot ethanol solution without homogenization (Figs. 2 and 4). This suggests that soluble carbohydrate in petal cells can be leached by decomposing cell membranes with hot ethanol; however, carbohydrate content determined using sorbitol, an internal standard, tended to increase as extraction proceeded (Fig. 2), indicating that an extraction process to obtain $\mathrm{C}$ solution is required to acquire appropriate data. We also confirmed that most carbohydrates were extracted by this process (Fig. 4). In rose petals, glucose, fructose, and sucrose are the major carbohydrate constituents, whereas methyl glucoside, xylose, and myo-inositol are minor sources (Ichimura et al., 1997). HPLC elution profiles revealed that carbohydrates in samples from the new method were well separated, as observed in those from the conventional method (Fig. 3). Few differences in carbohydrate content were observed using the new and conventional methods (Table 2 and Fig. 2). It takes less than $90 \mathrm{~min}$ from the time of preparing a plant sample until HPLC, versus more than a day using the conventional method. Furthermore, the new method does not require some of the apparatus of the conventional method, such as a centrifugal evaporator and homogenizer. Thus, the new method appears to be a simple and rapid method for the extraction of soluble carbohydrate from rose petals.

In carnations, glucose, fructose, sucrose, pinitol, and myo-inositol are soluble carbohydrate constituents (Ichimura et al., 1998). In Delphinium flowers, in addition to glucose, fructose, and sucrose, mannitol is a major carbohydrate (Ichimura et al., 2000). Previously, we reported that glucose, fructose, and sucrose are soluble carbohydrates in T. caerulea (Norikoshi et al., 2006). In the present study, these carbohydrates were also detected in extracts obtained using the new method. In the petals or sepals of these plants, few differences in carbohydrate content were observed between the new and conventional methods (Table 3). These results suggest that the new method could be used to extract soluble carbohydrate from petals or sepals of many floricultural plants.

No marked differences in soluble carbohydrate content were observed among leaves and stems in roses, carnations or Delphinium, using either the new or conventional method (Table4). This suggests that soluble carbohydrates can be extracted from leaves and stems of these plants by the new method; however, we have not yet confirmed that soluble carbohydrates can be extracted sufficiently from stem and leaf segments larger than those used in the present study. In addition, it remains unclear whether soluble carbohydrates can be extracted sufficiently from other plant materials. Thus, preliminary comparison between the new and conven- tional methods should be tested when soluble carbohydrates are extracted from such samples.

Previously, we reported an increase in sucrose concentration, and a decrease in glucose and fructose concentrations, with time in fluid obtained from frozen rose petals by centrifugation (Norikoshi et al., 2006). Since relatively high invertase activity is present in rose petals (Ho and Nichols, 1977), these changes in sugar concentrations may be the result of invertase activity. In the present study, however, the sugar content of samples stored for 1 week did not change over time (Table 1), suggesting that the carbohydrate content remains stable in these samples. This may be due to the inactivation of invertase in the samples by hot ethanol.

Differences in statistical variability were observed among data based on standard deviations (Tables 2, 3, 4 and Fig. 2). Carbohydrate content in petals varies with the developmental stage (Enomoto et al., 2004; Ichimura et al., 1998) and different parts of petals (unpublished result). In the present study, the amounts of organs used for extraction were small and sampling stages were not strictly determined. These sampling procedures could cause relatively large variability in some samples; however, standard deviations were relatively small in some samples, such as rose 'Chanel' petals and Delphinium sepals and leaves (Tables 2, 3, and 4). In most of these samples, non-significant differences were observed between the methods. Thus, the new method is suitable for determining carbohydrate content precisely from samples having low variability.

There were some differences in carbohydrate content between the new and conventional methods (Tables 2 , 3, 4 and Fig. 2). In particular, myo-inositol content was significantly greater with the conventional method than the new method in some results. We found that myoinositol is more hydrophilic than other carbohydrates detected in the present study (unpublished results). Ethanol solution at $99.5 \%$ was used in the new method. Thus, myo-inositol may not sufficiently be extracted by the new method. In addition, there were differences in sucrose content in the petals of T. caerulea and fructose in rose stems. Although carbohydrates were extracted from the same material sources, the samples used for extraction may occasionally have different carbohydrate content, leading to different results.

In the present study, sorbitol was used as an internal standard since we have previously confirmed a lack of sorbitol in all of the flowers used in this study; however, sorbitol occurs in some plants, including apples (Yamaki and Ino, 1992) and Phlox sublata (Enomoto et al., 2004). In these plants, galactose has been found to be suitable as an internal standard with the HPLC column used in the present study (Enomoto et al., 2004).

For flower opening, large amounts of soluble carbohydrate are required (Halevy and Mayak, 1979). Indeed, carbohydrate content in petals increases markedly during flower opening (Bieleski, 1993; 
Ichimura et al., 1998). Carbohydrate content in petals was found to vary depending on different parts of petals (unpublished result). To investigate the role of carbohydrate in petals for flower opening in detail, extractions of carbohydrates from many small tissues are required. Since many carbohydrate samples can be rapidly extracted by the new method developed in this study, this method appears to be useful. In addition to petals, this method could be applied to leaves and stems (Table 4). For many fruits, sugars are the most important determinant of their quality. Soluble carbohydrate also plays a role in stress tolerance, including tolerance to cold (Sasaki et al., 1996), drought (Keller and Ludlow, 1993), and salt (Sacher and Staples, 1985). The new method may be available to investigate the role of carbohydrates from these aspects.

In conclusion, soluble carbohydrates can be extracted by immersing petals in hot ethanol solution without homogenization. Based on this finding, we developed a simple and rapid extraction method of soluble carbohydrates from the petals or sepals of four floricultural plants. This method may be applied to other plant materials.

\section{Literature Cited}

Bieleski, R. L. 1993. Fructan hydrolysis drives petal expansion in the ephemeral daylily flower. Plant Physiol. 103: 213-219.

Dilley, D. R. and W. J. Carpenter. 1975. The role of chemical adjuvants and ethylene synthesis on cut flower longevity. Acta Hortic. 41: 117-132.

Doi, M., Y. Hu and H. Imanishi. 2000. Water relations of cut roses as influenced by vapor pressure deficits and temperatures. J. Japan. Soc. Hort. Sci. 69: 584-589.

Enomoto, H., K. Kohata, M. Nakayama, Y. Yamaguchi and K. Ichimura. 2004. 2-C-methyl-D-erythritol is a major carbohydrate in petals of Phlox sublata possibly involved in flower development. J. Plant Physiol. 161: 977-980.

Halevy, A. M. and S. Mayak. 1979. Senescence and postharvest physiology of cut flowers, part 1. Hort. Rev. 1: 204-236.

Ho, L. C. and R. Nichols. 1977. Translocation of ${ }^{14} \mathrm{C}$-sucrose in relation to changes in carbohydrate content in rose corollas cut at different stages of development. Ann. Bot. 41: 227-242.

Ichimura, K. 1998. Improvement of postharvest life in several cut flowers by the addition of sucrose. JARQ 32: 275-280.

Ichimura, K. and T. Hisamatsu. 1999. Effects of continuous treatment with sucrose on the vase life, soluble carbohydrate concentrations, and ethylene production of cut snapdragon flowers. J. Japan. Soc. Hort. Sci. 68: 61-66.
Ichimura, K., Y. Kawabata, M. Kishimoto, R. Goto and K. Yamada. 2003. Shortage of soluble carbohydrates is largely responsible for short vase life of cut 'Sonia' rose flowers. J. Japan. Soc. Hort. Sci. 72: 292-298.

Ichimura, K., M. Kishimoto, R. Norikoshi, Y. Kawabata and K. Yamada. 2005. Soluble carbohydrates and variation in vaselife of cut rose cultivars 'Delilah' and 'Sonia' flowers. J. Hort. Sci. Biotech. 80: 280-286.

Ichimura, K., K. Kohata and R. Goto. 2000. Soluble carbohydrate in Delphinium and their influence on sepal abscission in cut flowers. Physiol. Plant. 108: 307-313.

Ichimura, K., K. Kohata, M. Koketsu, M. Shimamura and A. Ito. 1998. Identification of pinitol as a main sugar constituent and changes in its content during flower bud development in carnation (Dianthus caryophyllus L.). J. Plant Physiol. 152: 363-367.

Ichimura, K., K. Kohata, M. Koketsu, Y. Yamaguchi, H. Yamaguchi and K. Suto. 1997. Identification of methyl $\beta$ glucopyranoside and xylose as soluble sugar constituents in roses (Rosa hybrida L.). Biosci. Biotechnol. Biochem. 61: $1734-1735$.

Ichimura, K. and K. Suto. 1999. Effects of the time of sucrose treatment on vase life, soluble carbohydrate concentrations and ethylene production in cut sweet pea flowers. Plant Growth Regul. 28: 117-122.

Keller, F. and M. M. Ludlow. 1993. Carbohydrate metabolism in drought-stressed leaves of pigeonpea (Cajanus cajan). J. Exp. Bot. 44: 1351-1359.

Koyama, Y., A. Uda, O. Wada and M. Fujimori. 1995. Effects of pre-conditioning budded carnation shoots prior to long-term cold storage on flower quality. J. Japan. Soc. Hort. Sci. 63: 835-842 (In Japanese with English abstract).

Norikoshi, R., H. Imanishi and K. Ichimura. 2006. A simple and rapid method for the extraction of soluble carbohydrate from petals in several flowers. Hort. Res. (Japan) 5: 459-464 (In Japanese with English abstract).

Ogiwara, I., Y. Ohtsuka, Y. Yoneda, K. Sakurai, N. Hakoda and I. Shimura. 1999. Extraction method by water followed by microwave heating for analyzing sugars in strawberry fruits. J. Japan. Soc. Hort. Sci. 68: 949-953.

Pun, U. K. and K. Ichimura. 2004. Role of sugars in senescence and biosynthesis of ethylene in cut flowers. JARQ 37: 219 224.

Sacher, R. F. and R. C. Staples. 1985. Inositol and sugars in adaptation of tomato to salt. Plant Physiol. 77: 206-210.

Sasaki, H., K. Ichimura and M. Oda. 1996. Changes in sugar content during cold acclimation and deacclimation of cabbage seedlings. Ann. Bot. 78: 365-369.

Yamaki, S. and M. Ino. 1992. Alteration of cellular compartmentation and membrane permeability to sugars in immature and mature apple fruit. J. Amer. Soc. Hort. Sci. 117: 951-954. 